values stated. The modern aeroplane has a ratio of lift to drag of 9 , and some of the light aeroplanes indicate a figure as high as I2 or I4, so that the best of the results on rotating cylinders compare very unfavourably with the aeroplane for efficiency.

Whatever may be the final utility of the rotating cylinder and the commercial fate of the Buckau, it may be expected that many attempts will be made to utilise the aspect of fluid motion brought into new prominence by the rotor ship. Whilst it is difficult to see immediate uses in aeronautics, there are certain directions in which speculation suggests the possibility of early benefit by a modified application of the principles involved in the propulsion of the rotor ship.

\title{
The Mountain Structure and Geographical Relations of South-Eastern Asia. ${ }^{1}$
}

\author{
By Prof. J. W. Gregory, F.R.S.
}

THE greatest mountain system in the world is 1 the Alpine-Himalayan, which forms the backbone of Europe and Asia. Its continuity has been proved from western Europe to eastern India. Its further eastward continuation has long been subject of controversy. According to one view it passed northeastward across central China to Bering Straits; according to another it was bent round against the mass of Chinese Tibet, and passed through western Burma to Sumatra and thence along the southern islands of the Eastern Archipelago. The interpretation of the mountain structure of Chinese Tibet is complicated by being due to movements at two different dates. The later mountains are of the same age as the Alps and Himalaya and are geologically modern. The other group is much older, and its fragments remain as highlands, which are the worn down stumps of the mountain foundations. The older system is represented in Europe by the Hercynian Mountains, and in Asia by the Altaids, members of which cross Chinese Tibet on lines approximately north and south, and continue southward as the Indo-Malayan Mountains. The Himalayan and Altaid Mountains meet in Chinese Tibet, and the mountain lines due to these two systems have to be carefully distinguished. The Himalayan movements have disturbed the grain due to the older Altaid folding and they admit of simplest proof where the rocks, were not in existence when the Altaid Mountains were made. For example, the folds and overfolds in the salt-bearing red sandstones of Yunnan must be post-Altaid, as those rocks were not in existence until after the Altaid movements. In other places the evidence is more complex. Some of the folds are too shallow to be Altaid, and the arrangement of the outcrop of the older rocks indicates upfolds on lines with the Himalayan trend.

The further extension of the Himalayan line eastward of Chinese Tibet is indicated by the claim of the French geologists in Tonkin that at the date of the Himalayan movements a band of country in southern China was pushed southward smashing the country in front of it. The existence of a rich mercury field in south-western China is also in favour of the country having been disturbed by intense mountain movements of the Himalayan period. The continuation of the main Alpine-Himalayan axis therefore appears to pass across southern China, and the Burmese-Malayan Arcs must belong to a loop to the south corresponding to the Atlas-Apennine loop around the western Mediterranean and the Syrian Arc beside the eastern Mediterranean.

1 From a discourse delivered at the Royal Institution on Friday, January 30.

NO. 289 I, VOL. I I 5$]$
The traditional cause assigned to such folding as that of the Alps and Himalaya is the contraction of the crust owing to the shrinkage of the earth. That theory has been repeatedly criticised in recent years owing to the contraction having been attributed to cooling; but there are more effective and more probable causes of contraction than cooling. That contraction has taken place is proved by the geological evidence. The restriction of the Alpine-Himalayan compression to a long narrow band, varying in latitude from $40^{\circ}$ to $48^{\circ}$ in Europe, and from $25^{\circ}$ to $38^{\circ}$ in Asia, is the natural result of that sinking of the northern dome of the world which is shown by the polar flattening. The junction of the northern dome with the tropical belt is naturally one of crumpling and crustal disturbance. This process would produce uplifts in the same zone of the crust around the northern hemisphere, and traces of this continuous upheaval are found. The West Indies and Central America include fragments of mountain chains formed at the same time as the Alps and with a similar trend.

The abrupt ending of the mountain grain of the continents on both sides of the Atlantic indicates the former extension of the land into the ocean. That the land once crossed the whole width of the Atlantic is supported by the biological evidence. Similar animals are found on opposite sides of the Atlantic in corresponding latitudes, and the resemblances of the South American and African faunas are not likely to be due to passage via Scotland and Greenland if there are no representatives of those groups in Europe or North America. The distribution of the ridges and deeps on the North Atlantic floor indicates uplifts in North America and western Europe at the time of the Alpine movements. There is similar evidence of former land extensions across the northern and southern Pacific, such as the occurrence of the alligator in the Yangtze Kiang, the resemblance of the flora of southern China to that of the south-eastern United States, and the occurrence on both sides of the South Pacific of various groups which are unrepresented in the lands on either side of the North Pacific. The biological evidence is supported by the ridges on the Pacific floor and the distribution of the coral islands. The former trans-Atlantic and trans-Pacific connexions must have endured until the time of the Alpine-Himalayan uplifts, for they were broken before the spread of the more specialised mammals and birds, and were available to some living groups of reptiles, amphibians, and specialised invertebrates.

The Indian Ocean was also once occupied by land, the disruption of which has affected the mountain structure of south-eastern Asia. At the end of the 
Altaid uplifts the site of the Indian Ocean was covered by a continent which extended from South America across the Old World to Australia. This continent, Gondwanaland, was broken up by successive subsidences; and the gulfs thus formed were gradually enlarged by further subsidences and so developed into the Atlantic and two basins of the Indian Ocean. These movements were accompanied by volcanic eruptions which deluged equatorial Africa and western India under floods of lava, while East Africa was torn asunder by the formation of the Great Rift Valley. If these eruptions and fractures were due to the formation of the Indian Ocean, it appeared strange that no corresponding phenomena were known on its eastern side. The evidence, however, is now clear that in Burma and western China there were volcanic eruptions which, though on a smaller scale, agree in date with the three main volcanic periods of East Africa; while meridional fractures of the same date as those which made the Great Rift Valley formed the great basins of Yunnan in western China. These fractures in Asia produced features different in some respects from those of East Africa, owing to the difference in structure between the continents. East Africa is an ancient solid plateau, whereas Yunnan has an extremely complex foundation due to the intersecting mountain folds. The fractures have therefore been less regular and shorter.

The date of the later movements in Chinese Tibet is indicated by the river system. The drainage of southeastern Tibet collects into three rivers which flow for I40 miles on parallel courses through a narrow belt, and instead of joining they then diverge, the Yangtze discharging into the China Sea 2000 miles from the mouth of its neighbour, the Salween. The present river system is the result of a long evolution controlled by the mountain-forming movements. The drainage of central and south-eastern Asia in pre-Himalayan times was probably mainly through broad east to west trending valleys due to a gentle buckling of the earth's crust. The Himalayan movements confirmed this system; but during the subsequent settling down of the country the eastward outlet of the Tibetan rivers was reduced and Tibet became a land of lakes, to an extent even greater than it is now. Their level rose until they found outlets to the south, through lines of weakness along the Altaid grain. The Tibetan rivers through these southern outlets discharged to the South China Sea. The upper Brahmaputra or Tsangpo discharged through the Dihang, crossed the site of Assam, and passed through the Hukong Gap to the Irrawadi. The Tibetan section of the Yangtze Kiang flowed through Tali Lake to the Red River of Tonkin. Further earth movements broke up this system and diverted its western member through the valley of Assam as the Lower Brahmaputra to the Bay of Bengal, and the eastern by a series of deep gorges and striking zigzags across eastern China to the South Pacific.

The geographical relations of the mountains of southeastern Asia therefore indicate that the Alpine-Himalayan System is a crumpled band of the crust, where the in-sinking northern dome of the world pressed against the tropical belt. The east to west ridges on the floors of the North Atlantic and North Pacific may be attributed to the same forces as produced the Alps and the Himalaya; and the east to west trending mountains, of which remnants are the dominant features in the topography of the West Indies and central America, are also an expression of the buckling of the crust of the Northern Hemisphere where the northern dome of the earth meets its tropical and subtropical belt.

\section{Recent Developments in the Nitrogen-fixation Industry.}

WHEN the historian of the future writes concerning the influence of scientific discovery and achievement upon civilisation, we may be sure that he will have much to say about the political and economic effects of the development of the nitrogenfixation industry. Of all the material factors that helped to make the War the greatest and most devastating conflict in human history, the possession by the Germans of adequate plant for making synthetic ammonia, and of adequate personnel for working it, was probably the most important. Since that time the processes for fixing atmospheric nitrogen have been further developed, and the present yearly production of fixed nitrogen is approximately 500,000 metric tons, three-quarters of which is made in Germany.

The arc process, the lineal descendant of Cavendish's initial discovery in 1783 , now contributes only a relatively small proportion of the total production, namely, about 36,000 m.t., its high power-requirement rendering it uneconomical save in countries possessing cheap and abundant water-power. The modification of the process involving the use of oxygen-enriched air, which was worked principally in Switzerland and Germany until I92I, had to be abandoned owing to the serious explosions to which it gave rise. The Swiss Nitrum Co., which worked it on a large scale, has recently adopted the Claude process in its stead.
Fixation by means of calcium carbide was developed enormously during the War, but the present outlook for this method is not promising: calcium cyanamide has not come up to expectations as a nitrogenous fertiliser, and the power-requirement, although only about one-fifth that of the arc process, is 3-4 times greater than that of the direct synthetic-ammonia process. The output of cyanamide has declined to about $x 40,000$ m.t. per annum, and about one-half of the world's plant capacity is unutilised. There are, however, still possibilities, for cyanamide can be used as an intermediate product in the manufacture of urea, of ammonia, and of "Ammo-phos," a fertiliser made on a small scale in the United States.

Urea appears to be the nitrogenous fertiliser of the future. It is the most concentrated of its class ; it can be transported and used without difficulty; it leaves neither acid nor alkali behind in the soil ; and it has given general satisfaction in experimental work. It will probably be manufactured by combining synthetic ammonia and carbon dioxide at high temperature and pressure. Since r 922 a combination of urea and acid phosphate, called "Phosphazote" has been made in Switzerland, and a large works in Norway is to start its production early in the current year.

The Haber process and its modifications, involving the direct union of nitrogen (from liquid air) and

$$
\text { NO. } 2891 \text {, VOL. I I } 5]
$$

